\title{
Financiamento federal da Atenção Primária à Saúde no Sistema Único de Saúde - SUS: uma revisão integrativa
}

\author{
Danilo Aquino AMORIM ${ }^{(1)}$ \\ Áquilas Nogueira MENDES(1) \\ ${ }^{(1)}$ Faculdade de Saúde Pública, Universidade de São Paulo - USP, São Paulo, SP, Brasil.
}

Recebido: 28 jan 2019 Aceito: 10 fev 2019

Autor de correspondência:

daniloamorim_5@hotmail.com

Conflito de interesses: Os autores declaram não haver nenhum interesse profissional ou pessoal que possa gerar conflito de interesses em relação a este manuscrito.

\section{Resumo}

No Brasil, a partir da criação do Sistema Único de Saúde - SUS, a Atenção Primária à Saúde - APS tornou-se a principal estratégia de reorientação do modelo assistencial e ampliação do acesso aos serviços de saúde. Paralelamente a essa reorientação, a operacionalização da política de saúde foi alterada, isto é, houve avanço do processo de municipalização, da coordenação dos municípios em nível das regiões de saúde e do estabelecimento de novas sistemáticas para o financiamento das ações e serviços de saúde, especialmente em nível da atenção básica. Diversos estudos demonstram os impactos da Estratégia de Saúde da Família - ESF) na saúde da população brasileira, destacando-se a redução da mortalidade infantil e de hospitalizações evitáveis, a ampliação do acesso a ações e serviços de saúde e a redução de desigualdades sociais em saúde. Mesmo diante de avanços relevantes, ainda são enumerados diversos desafios para a consolidação de APS no Brasil, entre eles o financiamento. Há evidências de que sistemas universais estruturados a partir de uma APS forte e com financiamento e prestação predominantemente públicos apresentam resultados superiores em termos de qualidade, eficiência e equidade em saúde. Na América Latina, observam-se diferentes arranjos de financiamento que se relacionam aos modelos de atenção primária à saúde, variando de transferências do nível central a programas específicos (Argentina, Equador, Guiana, Venezuela) tendo, ainda, como base alocação de valores per capita, como nos casos de Brasil e Chile. No caso brasileiro, o financiamento da atenção básica se dá em composição tripartite, sendo que o Piso da Atenção Básica - PAB constitui-se no componente federal para o financiamento da APS, composto de uma fração fixa e outra variável. O PAB Fixo é destinado ao financiamento das ações de atenção básica em geral, estabelecido por um valor per capita/ano. O PAB Variável é composto de incentivos que o Ministério da Saúde repassa sempre que os municípios se comprometam a realizar práticas determinadas ou façam adesão a formas de organização da APS propostas pelo Ministério da Saúde. De uma forma geral, os valores transferidos pelo Ministério da Saúde são insuficientes para financiar uma APS integral e resolutiva, fazendo com que os municípios se responsabilizem por parcela considerável do financiamento da APS ou levando a estruturação de uma APS seletiva e focalizada. A estruturação de uma APS integral no âmbito de um 
sistema universal de saúde, enquanto expressão de cidadania plena passa necessariamente pelo fortalecimento do financiamento do SUS, através de sua expansão e da inibição da captura do fundo público pelo capital privado. Essa é uma demanda histórica dos movimentos em defesa da saúde pública no Brasil, que esbarra em constrangimentos políticos e econômicos impostos pelo capitalismo contemporâneo financeirizado e sua crise estrutural. Há necessidade de catalogar os estudos na área de economia da saúde voltados ao financiamento da atenção básica, de forma a compreender o desenvolvimento histórico da APS no Brasil, o contexto de sua expansão, os constrangimentos impostos para sua consolidação, a relação das formas de transferências de recursos com a conformação de modelos assistenciais locais e o atendimento das necessidades de saúde da população brasileira. Objetivo: o objetivo do estudo é analisar o financiamento federal da atenção primária à saúde no SUS no período de 1988 a 2018, através de levantamento, organização e sistematização da produção científica sobre o tema no período definido, seguido de análise dos aspectos que conformaram o financiamento e as características da atenção primária à saúde no SUS ao longo dos 30 anos de sua existência. Método: tratase de revisão integrativa da literatura, norteada a partir da seguinte pergunta: "O que a literatura científica apresenta sobre o financiamento federal da atenção primária à saúde no Brasil nos últimos 30 anos de existência do SUS?". A partir da pergunta de pesquisa foi possível definir os seguintes itens-chave: (1) financiamento; (2) atenção primária à saúde; e (3) SUS. Por meio dos itens-chave foi possível derivar os descritores através da plataforma Descritores em Ciências da Saúde - DeCS. Os descritores derivados de cada item-chave são os seguintes: (1) Gastos em Saúde; Custos de Cuidados de Saúde; Investimentos em Saúde; Recursos Financeiros em Saúde; e Financiamento da Assistência à Saúde; e (2) Atenção Primária à Saúde; Serviços Básicos de Saúde; Saúde da Família; e Estratégia Saúde da Família. Foi utilizado o Portal Regional da Biblioteca Virtual em Saúde - BVS para pesquisa e recuperação das publicações. Considerações Finais: a estratégia de busca definiu a seguinte sintaxe final: (mh:("Gastos em Saúde")) $O R$ (mh:("Custos de Cuidados de Saúde")) $O R$ (mh:("Investimentos em Saúde")) $O R$ (mh:("Recursos Financeiros em Saúde")) $O R$ (mh:("Financiamento da Assistência à Saúde")) $A N D$ (mh:("Atenção Primária à Saúde")) $O R$ (mh:("Serviços Básicos de Saúde")) OR (mh:("Saúde da Família")) OR (mh:("Estratégia Saúde da Família")) AND (mh:("Sistema Único de Saúde")). A busca final resultou em um total de 151 estudos. Fez-se necessário, no entanto, aplicar alguns critérios de exclusão para esses resultados. Foram excluídas publicações na modalidade pesquisa bibliográfica, revisões, monografias, teses, dissertações, editoriais e cartas ao editor.

Descritores: Gastos em Saúde; Financiamento da Assistência à Saúde; Atenção Primária à Saúde; Sistema Único de Saúde. 